\title{
A PRÁTICA DO ECODESIGN NA CONSTRUÇÃO CIVIL E A BUSCA PELO DIREITO FUNDAMENTAL AO MEIO AMBIENTE ECOLOGICAMENTE EQUILIBRADO
}

\author{
G. B. M. Rezende ${ }^{1}$, A. L. C. Brito ${ }^{2}$, L. S. Freitas ${ }^{3}$ \\ ${ }^{1,2}$ Universidade Federal de Mato Grosso, ${ }^{3}$ Universidade Federal de Campina Grande \\ greycebernardes@yahoo.com.br
}

Submetido 08/01/2016 - Aceito 20/07/2017

DOI: $10.15628 /$ holos.2017.3961

\section{RESUMO}

A Carta Magna garante a todos o direito ao meio ambiente ecologicamente equilibrado. Essa proteção é reforçada por meio de instrumentos de comando e controle eficientes, que buscam a efetivação da preservação, melhoria e recuperação da qualidade ambiental propícia à vida. Do ponto de vista do sistema de gestão ambiental essa proteção é alcançada pela implantação de diversas ferramentas que podem ou não se complementar. Uma destas ferramentas é o Ecodesign, que insere o aspecto ambiental em novos produtos, processos ou serviços. O objetivo deste artigo é apontar as interfaces existentes entre a utilização do
Ecodesign como ferramenta de gestão ambiental, e sua contribuição para viabilizar o direito fundamental ao meio ambiente ecologicamente equilibrado. A interface desses instrumentos de proteção reforça a ideia de que a proteção do meio ambiente é universal. Para tanto, é feita a análise dos aspectos do Ecodesign nas etapas previstas na construção civil através do check list de Ottman; otimizado e adaptado para o contexto das construções. Os resultados evidenciaram que os aspectos do Ecodesign viabilizam um meio ambiente ecologicamente equilibrado, demonstrando uma importante interface entre o Ecodesign e o direito.

PALAVRAS-CHAVE: sistemas de gestão ambiental, ecodesign, construção civil.

\section{THE PRACTICE OF THE ECODESIGN IN THE CONSTRUCTION AND THE SEARCH FOR FUNDAMENTAL RIGHT TO AN ECOLOGICALLY BALANCED ENVIRONMENT}

\begin{abstract}
The Constitution guarantees everyone the right to an ecologically balanced environment. This protection is reinforced through instruments of command and effective control, seeking of the preservation, improvement and recuperation of environmental quality conducive to life. From the point of view of the environmental management this protection is achieved by the deployment of several tools that may or may not be complementary. One such tool is the Ecodesign, which inserts the environmental aspect into new products, processes or services. The purpose of this article is to point the interfaces between the use of
\end{abstract}

Ecodesign as tool for environmental management and its contribution to the viability of the fundamental law to an ecologically balanced environment. The interface of these instruments reinforces the idea that environmental protection is universal. So, is made an analysis of the aspects of Ecodesign in planned stages in construction through the check list Ottman, optimized and adapted to the context buildings. The results showed that aspects of Ecodesign enable an ecologically balanced environment, demonstrating an important interface between Ecodesign and the law.

KEYWORDS: environmental management systems, eco-design, construction, environmental law. 


\section{INTRODUÇÃO}

É notória a importância da construção civil na economia brasileira, uma vez que é responsável pela construção de obras residenciais, comerciais ou de infraestrutura, e consequentemente fomenta a produção e comercialização de produtos utilizados na parte básica e nos acabamentos dessas obras, como cimento, azulejos, pisos etc. Além disso, é socialmente importante pois diminui o déficit habitacional e contribui para a geração de empregos, seja diretamente na construção, ou ainda nas fábricas que produzem os produtos destinados ao setor.

Contudo a produção de resíduos nesse processo construtivo é um fator que tem causado grande preocupação, uma vez que a falta de destinação adequada desses resíduos acaba degradando ainda mais o meio ambiente, além de causar intervenções na paisagem urbana e muitas vezes no patrimônio natural.

Por outro lado, a escolha adequada de materiais, técnicas construtivas e processos na construção civil vêm se consolidando como uma prática importante para a sustentabilidade, diminuindo o impacto ambiental causado pelo setor, reduzindo o consumo energético e otimizando custos.

Dentro desse contexto, a aplicação do Ecodesign objetiva projetar ambientes, desenvolver produtos e executar serviços que podem reduzir a utilização dos recursos nãorenováveis, ou ainda minimizar seu impacto durante o ciclo de vida (Ministério do Meio Ambiente, 2011).

Evidencia-se, portanto, que a correta gestão ambiental, acompanhada também de um arcabouço legal que regulamente as práticas na construção civil, certamente viabilizarão um processo construtivo mais seguro, tanto para a preservação ambiental, quanto a qualidade de vida da população.

Nessa seara, o presente artigo aponta as interfaces existentes entre a utilização do Ecodesign como ferramenta de gestão ambiental e sua contribuição para viabilizar direito fundamental ao meio ambiente ecologicamente equilibrado.

\section{DIREITO FUNDAMENTAL AO MEIO AMBIENTE ECOLOGICAMENTE EQUILIBRADO E O ECODESIGN}

A finitude e insuficiência dos recursos naturais, utilizados de forma desmedida para suprir as necessidades da população mundial, está mais do que evidente, hodiernamente, ainda mais quando se verifica que as atividades humanas usam de tais recursos indiscriminadamente, em prol da obtenção de um acelerado desenvolvimento econômico.

Não há dúvida de que a humanidade está sujeita a severos problemas ambientais decorrentes da utilização desmedida dos recursos naturais. Por isso, torna-se imprescindível a compreensão da extensão e dos limites de tolerabilidade dos prejuízos ambientais advindos das atividades humanas que lesam alguns bens ambientais juridicamente tutelados bem como a 
adoção de medidas e práticas que controlem a utilização indiscriminada de recursos naturais imprescindíveis para a vida humana.

Sabe-se que a relação existente entre o desenvolvimento econômico e a proteção do meio ambiente é a questão central da proteção das futuras gerações. A discussão que se deve realizar sobre essa relação deve começar, então, pela constatação de que os tempos atuais são marcados por uma sociedade produtora de riscos globais ambientais, onde o homem, inevitavelmente, convive com ameaças decorrentes dessa sociedade, e que se apresentam na ordem política, tecnológica, econômica, cultural e, principalmente, ecológica.

Tudo isso leva a crer na configuração da Teoria da Sociedade de Risco, que nas palavras de Leite (2010), é uma teoria que retrata uma transformação social ocorrida na fase posterior ao período industrial clássico, representando a percepção do esgotamento do modelo de produção, e destacando o risco permanente da ocorrência de desastres e catástrofes, em consequência do crescimento econômico.

A constituição de uma sociedade de risco é constatada, primeiramente, por Ulrich Beck, criador da ideia de que a humanidade, hodiernamente, não detém conhecimentos seguros sobre a possível nocividade das atividades tecnológico-científicas decorrentes da sociedade pósindustrial. Para Beck (1997), há a consciência da existência dos riscos sem haver, contudo, uma política adequada de gerenciamento desses riscos - o que implica na constatação de uma irresponsabilidade organizada.

É nesse sentido que a construção e consagração do conceito de meio ambiente como um direito fundamental, cuja implementação depende da atuação e responsabilidade solidária entre Estado e coletividade (esfera pública e privada), faz-se por necessário e é o ponto de partida para se compreender que o uso ilimitado dos recursos naturais, decorrentes de apropriações inadequadas, expansão demográfica ou do consumismo exacerbado, permite a aparição de riscos/perigos de ordem tecnológica, industrial e, sobretudo, ecológica. O que se percebe, atualmente, é que a expansão tecnológica e científica ocorrida nas últimas décadas é uma das responsáveis pela atual crise ambiental carente de meios e instrumentos que controlem e disciplinem, precisamente, o imoderado crescimento econômico.

Registra-se que a sociedade atual dispõe de um modo de vida calcado quase que exclusivamente em práticas e costumes capitalistas, cujas origens remontam à Idade Média. Ressalta-se que se trata de um modelo econômico marcado pelo antropocentrismo, e assim desenvolveu-se ao longo dos séculos, expandindo-se principalmente na época da Revolução Industrial, compreendendo e compondo, desta forma, o sistema social e econômico atual.

Devido à compreensão da lógica capitalista de que homem está no centro de tudo e todos, o modelo de produção propagado durante o ápice do desenvolvimento industrial e econômico (aliado à globalização) no século XX possuía embasamento na percepção de que a natureza e seus recursos eram infinitos, sendo o planeta Terra fornecedor de recursos ilimitados.

Acontece que essa lógica antropocêntrica, no que diz respeito à proteção do meio ambiente, já tem mostrado o seu lado perverso, principalmente quando vemos o esgotamento de recursos naturais causados pela atuação desenfreada do modo de produção e consumo 
humano. A constatação de que o homem deve viver harmoniosamente com o meio ambiente, sob pena de extinção da própria espécie; associado, ainda, à ideia de que nós pertencemos a um todo maior, e que por isso, as nossas ações sempre devem observar a finitude dos recursos naturais; indica que essa relação de interdependência homem-recursos naturais não pode mais ser vista, exclusivamente, sob um viés antropocentrista. Nesse sentido, Leite e Ayala (2011) apontam que a concepção de que o homem submete a natureza à exploração ilimitada perdeu seu fundamento. Por meio do desenvolvimento da ecologia, percebeu-se que a intervenção humana não apenas acaba com os recursos naturais não renováveis, mas consequentemente traz perigo ao equilíbrio do ser humano no planeta. A tendência atual é evoluir numa perspectiva menos antropocêntrica, mediante a busca pela proteção integral do meio ambiente.

Outra lógica perversa compreendida à época da Revolução Industrial foi a de que não haveria avanço na produção de bens e serviços sem que houvesse, inevitavelmente, geração de poluentes, prevendo ainda que, num futuro próximo, surgisse alguma tecnologia que pudesse reverter tal quadro de poluição e deterioração do meio ambiente.

Diante desta delicada situação, por volta dos anos de 1970, notou-se o surgimento dos primeiros órgãos de controle da poluição, juntamente com as legislações ambientais e o monitoramento e fiscalização da qualidade ambiental das indústrias, surgindo posteriormente os primeiros sistemas de gestão ambiental (SGA). No entanto, foi a partir dos anos 1990 que a utilização de ferramentas de gestão ambiental voltados para o meio ambiente e consequente redução dos impactos ambientais tem tomado maiores proporções e tem se apresentado como importante instrumento complementar da legislação na proteção ambiental (Nascimento \& Venzke, 2006).

Pode-se dizer que este surgimento é reflexo do crescimento da consciência ambiental oriunda da preocupação dos impactos ambientais gerados pelo desenvolvimento industrial e econômico.

O Ecodesign surge, nesse contexto, como um importante instrumento de promoção do direito fundamental ao meio ambiente ecologicamente equilibrado, além de ser compreendido também como ferramenta de gestão ambiental, que busca a inserção de aspectos ambientais na criação de novos produtos, processos ou serviços. É possível identificar ainda que essa ferramenta coaduna com os anseios do texto constitucional (art. 225, caput, CF/88, art.225, V, CF/88) e demais legislações infraconstitucionais (Lei 6938/81, Resolução 237 Conama) no que diz respeito à proteção do meio ambiente, uma vez que considera que as fases de composição de um produto (fase de pré-produção, fase de produção, distribuição, uso do produto, descarte ou reutilização) devem visar à diminuição dos impactos ambientais oriundos de atividades que geram a escassez de recursos naturais, o crescente consumo energético, etc.

Importa destacar que as definições e aplicações do Ecodesign tomam variáveis diversas quando abordadas por diferentes autores. Desse modo, muito se discute sua aplicação quanto à eficiência e estética dos produtos, quanto ao custo e satisfação do consumidor e a relação desse conjunto com o ambiente e a sociedade. Não menos importante, se observa a íntima proposta em atender as questões supracitadas sem deixar de satisfazer os interesses mercadológicos e 
lucrativos das empresas, seja atraindo o consumidor pelo design do produto ou do projeto, ou mesmo com a redução de despesas pela empresa para a concepção destes.

Outrossim, tendo em vista as inúmeras medidas adotadas para a efetiva aplicação do Ecodesign, é indispensável observar as estratégias ligadas às várias fases do mesmo como reflexos das necessidades a que faz jus um ambiente ecologicamente equilibrado e que, portanto, devem ser consideradas pelas empresas.

Muito embora seja o desafio e objetivo maior do Ecodesign produzir bens e serviços em harmonia com um ambiente ecologicamente equilibrado, a realidade observada acaba, muitas vezes, seguindo dimensões diversas, ao passo que muitas empresas utilizam o Ecodesign como atrativo aos consumidores, destoando o seu real objetivo e atribuindo ao mesmo a busca por lucros.

Observa-se que a proteção dos recursos naturais e do meio ambiente tem sido subsidiada pela atuação limitada dos mecanismos de comando e controle existentes no ordenamento jurídico. ${ }^{1}$ Nesse sentido, o emprego dessa ferramenta de gestão ambiental, pode ser também uma estratégia eficaz para a proteção do meio ambiente, frente ao desenvolvimento. Tudo isso se justifica na compreensão de que a exigência da utilização sustentável dos recursos naturais, embora prevista em documentos internos e internacionais, ainda não logrou encontrar na política jurídico-ambiental mecanismos consistentes que permitam a sua real implementação.

Com efeito, a proteção dos recursos naturais frente à atual crise ecológica impõe a reflexão sobre a necessidade de articulação e atuação de novas formas de defesa dos bens ambientais, ou seja, a criação de novas culturas ecológicas, e talvez aí encontra-se a importância da utilização do Ecodesign como ferramenta de gestão ambiental. Como afirma Leff (2000), a cultura ecológica pressupõe a elaboração de uma nova racionalidade ambiental, através de processos de estabelecimento de critérios axiológicos de ética ambiental; construção de uma teoria ambiental através da transformação de conceitos, técnicas e instrumentos com a finalidade de avançar a estilos de desenvolvimento sustentável; e ainda a mobilização de diversos grupos sociais, que busquem implementar projetos de gestão participativa baseada no ambientalismo.

\section{O ECODESIGN E AS ESTRATÉGIAS PARA SUA APLICAÇÃO}

Analisando as definições de Ecodesign propostas por Fiksel, Peneda e Frazã, nota-se que o Ecodesign como ferramenta busca uma visão sistêmica do desempenho do projeto, pontuando objetivos ambientais, de saúde e segurança e atributos como estética e ergonomia. É através de uma análise do ciclo de vida do produto ou processo que se fundamenta a ecoeficiência, que busca a ligação entre eficiência dos recursos e responsabilidade ambiental (Nascimento \& Venzke, 2006).

O Ecodesign tem seu campo de atuação na concepção de novos conceitos e no surgimento de novos padrões de consumo. Integra as questões ambientais no design industrial, relacionando o que é tecnicamente possível com o que é ecologicamente necessário e

\footnotetext{
${ }^{1}$ Pode-se citar o Estudo de Impacto Ambiental e o Zoneamento Ecológico-Econômico.
} 
socialmente aceitável, em face da percepção crescente das necessidades de salvaguardar o ambiente num contexto de desenvolvimento sustentável (Annes, 2003).

Já o PNUMA (Programa das Nações Unidas para o Meio Ambiente) utiliza a Teia das Estratégias do Ecodesign para fazer a avaliação do desempenho de vários aspectos relacionados à um produto, conforme a Figura 1 de Nascimento e Venzke (2006).

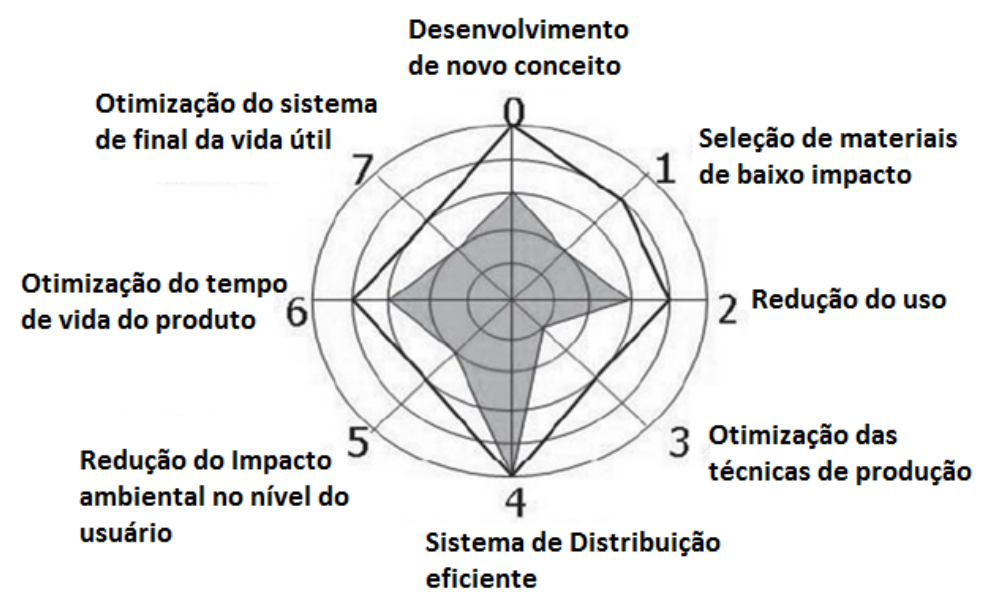

Figura 1: Teia das Estratégias do Ecodesign. Fonte: Nascimento e Venzke (2006).

Na orientação para o uso dessa ferramenta de avaliação do desempenho ambiental de um produto, o usuário poderá atribuir para cada círculo um percentual, como por exemplo, o centro dos círculos corresponde a zero e, com uma variação de 20 pontos percentuais a cada círculo, chega-se ao círculo mais externo com uma pontuação de $100 \%$, ou seja, o centro da Figura representa um desempenho ambiental inadequado e no círculo mais externo, ótimo desempenho ambiental. Ao realizar uma análise das probabilidades de melhorias, é marcado nos mesmos raios qual será o desempenho ambiental do produto após a aplicação das medidas estabelecidas (Nascimento \& Venzke, 2006).

Há também o check list de Ottman (1997), a qual elaborou questões que ao serem respondidas, fornecem um meio de aplicação do Ecodesign nas várias fases do produto: 


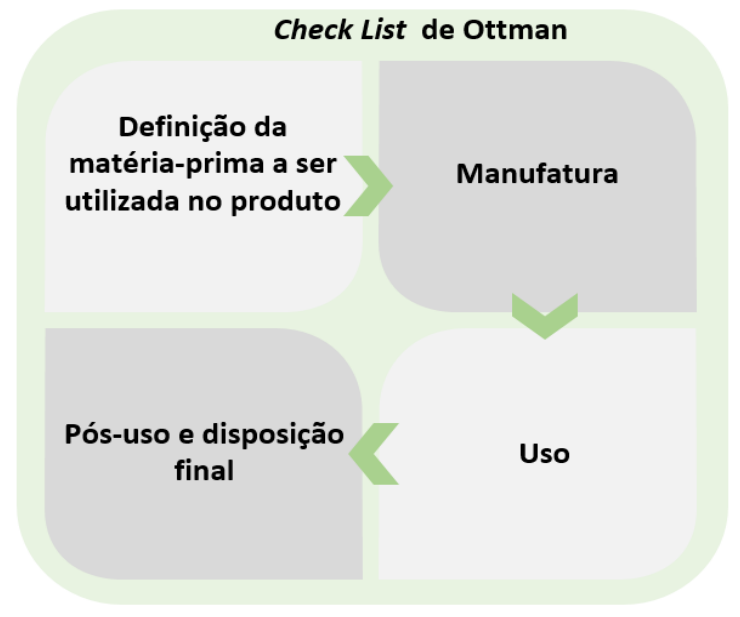

Figura 2: Aspectos analisados no check list de Ottman. Fonte: adaptado de Ottman (1997).

A Figura acima demonstra de forma sucinta os quatro aspectos analisados no check list de Ottman. No próximo capítulo, serão apresentadas essas etapas de forma detalhada, e enfatizando a utilização do Ecodesign na busca pela construção civil sustentável. Ao final será elaborado um check list específico para a construção civil a partir do modelo de Ottman.

\section{A PRÁTICA DO ECODESIGN NA CONSTRUÇÃO CIVIL}

A construção civil é fonte para diversos fatores de impacto ambiental, desde a escolha e utilização de materiais, desperdício e produção de resíduos no processo de construção da edificação até o baixo desempenho ambiental da edificação já concluída.

Abaixo analisa-se, a partir do check list de Ottman (1997), as várias fases da construção civil, que podem ser otimizadas conforme princípios do Ecodesign:

\section{1- Etapa: Definição da matéria-prima a ser utilizada no produto}

Nesta etapa, Ottman evidencia que alguns aspectos relacionados à matéria-prima devem ser estudados. Tais como: minimizar o potencial nos processos de compra de matérias-primas a fim de evitar o desmatamento das florestas tropicais, o derramamento de óleo, o fraccionamento da terra; ou ainda pode-se utilizar recursos renováveis ou recursos que são sustentavelmente gerenciados.

É neste contexto que na construção civil surgem os chamados materiais nãoconvencionais, que são materiais que despendem menor quantidade de energia e poluentes no seu processo de fabricação, geram menos resíduos, e podem ser reincorporados pela natureza mais facilmente. Em contrapartida há os materiais convencionais industriais não-renováveis, como aço e cimento, que provocam poluição na atmosfera, emitindo CO2 pelo uso de carvão e petróleo na sua produção e transporte dos mesmos (Ghavami, 1993).

Dentre os vários materiais não-convencionais que surgem como alternativas de materiais menos poluentes, renováveis e de baixo custo, cita-se o bambu e o tijolo ecológico. 
- Tijolo Solo-Cimento BTC: é um tijolo composto por solo (areia argilosa), água, um pouco de cimento e comprimido em prensas mecânicas. O seu processo de cura não passa por queima, gerando um menor impacto ambiental na sua produção.

- Bambu: encontra centenas de aplicações na construção civil, é encontrado em abundância nas partes tropicais e sub-tropicais do planeta e apresenta propriedades excelentes. Além disto, o bambu atua como filtro do ar, absorvendo $\mathrm{CO} 2$ e produzindo oxigênio, é preciso pouca energia para transformá-lo em elementos estruturais de cobertura como estruturas espaciais, treliças planas em tubos para condução de água e em elementos de reforço de concreto, substituindo o aço. Abaixo imagens de edificações que utilizaram o bambu, disponíveis em Queiroz, Capello e Wenzel (2007). A Figura 3 representa o estacionamento do zoológico municipal de Leipzing, na Alemanha, que foi construída com varas de bambu presas em cintas de aço. Já a Figura 4, retrata o interior do Aeroporto Internacional de Barajas, na Espanha. Seu enorme forro é feito com bambu.

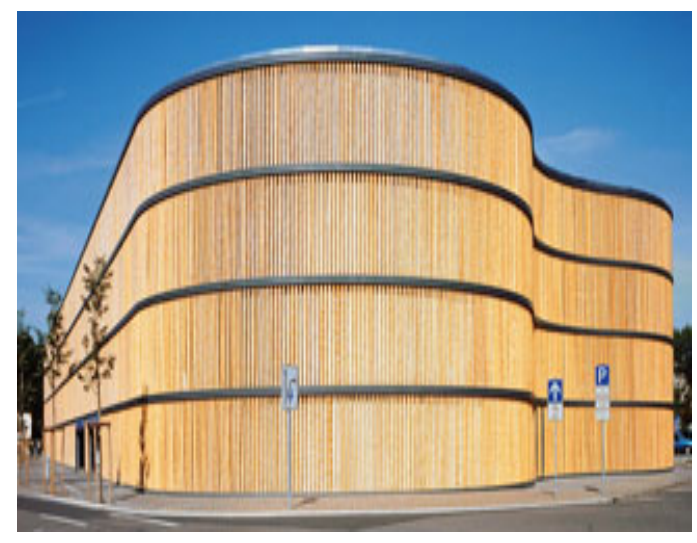

Figura 3: Estacionamento feito com bambu. Fonte: Queiroz, Capello e Wenzel (2007).

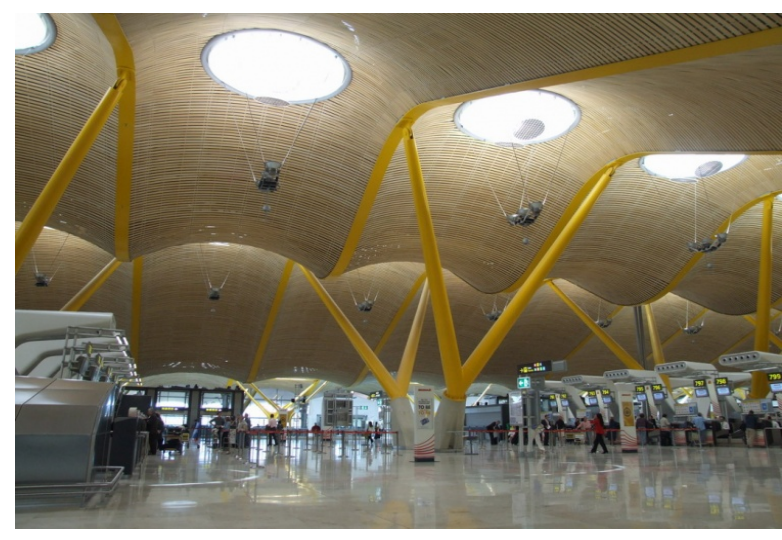

Figura 4: Interior do Aeroporto Internacional de Barajas. Fonte: Queiroz, Capello e Wenzel (2007).

Ressalta-se que no Brasil, há vários outros tipos de materiais não-convencionais como: alvenaria de garrafas PET (polietileno tereftalato), compósito com raspas de pneu, látex para isolamento térmico e lã de PET, enfim, materiais que buscam a utilização racional dos recursos naturais e o aproveitamento de resíduos.

\section{2- Etapa: Manufatura}

Nesta etapa, Ottman ressalta que deve-se analisar os passos a serem adotados para prevenir ou reduzir a produção de resíduos sólidos perigosos no processo de produção. Também verificar como reduzir o consumo de água e energia e as emissões e efluentes.

No contexto da construção civil, verifica-se que esta é uma das etapas onde mais necessita-se de gestão quanto à produção de resíduos sólidos e desperdícios.

No Brasil, alguns aspectos do processo de construção da edificação merecem destaque como a falta de planejamento das etapas de trabalho, o que gera retrabalho, "quebra-quebra" e 
principalmente desperdício de materiais; além da inexpressiva gestão do resíduo produzido e o não atendimento à Resolução do Conselho Nacional do Meio Ambiente - CONAMA 307/2002.

A resolução CONAMA 307/2002, estabelece que geradores de resíduos na construção civil deverão ter como objetivo prioritário a não geração dos resíduos, buscando, secundariamente, a redução, a reutilização, a reciclagem e a destinação final. A resolução também proíbe a disposição em aterros sanitários, em bota- foras, em encostas, corpos d'água, lotes vagos e áreas protegidas por lei.

Portanto evidencia-se nesta etapa a necessidade de um bom planejamento e gerenciamento das obras para evitar desperdícios e perdas no processo produtivo.

\section{3- Etapa: Uso}

No check List de Ottman, deve-se se tomar as devidas interrogações para esta etapa:

- Pode-se redesenhar os produtos para torná-los mais eficientes no consumo de energia e também reduzir os custos operacionais?

- Pode-se elaborar produtos mais seguros ou mais agradáveis ao uso?

- Pode-se utilizar ingredientes alternativos que ajudem a minimizar os riscos à saúde e ao meio ambiente?

Para tanto, na construção civil, vários aspectos podem ser pensados para melhorar o desempenho ambiental do edifício em relação ao seu uso, que serão comentados a seguir:

a) Reutilização de água:

Sabe-se que a água é um recurso renovável, porém os meios naturais de obtenção da água potável são frágeis e limitados. Para tanto, o reuso planejado da água já é uma solução adotada com sucesso em vários países, e podendo ocorrer através da captação das água pluviais ou reuso das águas servidas (Pereira, 2009).

Reusar a água também oferece benefícios porque reduz sua demanda, além de proteger o meio ambiente, economizar energia, reduzir investimentos em infra-estrutura e proporcionar melhoria dos processos industriais.

b) Conforto Ambiental e Eficiência Energética

O estudo de conforto ambiental é dividido usualmente em três grandes grupos: conforto térmico, lumínico e acústico. Diversos aspectos são estudados em conforto ambiental: a otimização da ventilação natural, da iluminação natural, emprego de arborização, telhados verdes etc. Estes aspectos influenciam também na eficiência energética da edificação.

Com um melhor aproveitamento das condições climáticas locais, um imóvel pode ser construído com uma maior ventilação, o que permite o uso moderado de ar condicionado, ou ainda, pode receber maior radiação solar, aproveitada por um aquecedor solar.

Para Lamberts, Dutra e Pereira (2014) a eficiência energética pode ser entendida como a obtenção de um serviço com baixo dispêndio de energia. Portanto, um edifício é mais eficiente 
energeticamente que outro quando proporciona as mesmas condições ambientais com menor consumo de energia. Assim o conceito de eficiência energética foi criado para que o consumo de energia seja repensado em prol da sustentabilidade.

c) Fontes Alternativas de Energia

Também relacionado com a eficiência energética das edificações, cita-se o uso de fontes alternativas de energia, como a energia solar e a energia eólica.

Em edificações residenciais, o aproveitamento da energia solar já é bastante difundido. A energia solar, é a energia que deriva dos raios solares que pode ser convertida pela via fotovoltaica para produzir eletricidade ou pela via térmica para produzir calor e/ou eletricidade (Vichi \& Mansor, 2009).

Ressalta-se que alguns destes aspectos aqui abordados, foram regulamentados recentemente no Brasil pela norma ABNT NBR 15575/2013 - Norma de Desempenho para Edificações Habitacionais em vigor desde o dia 12 de maio de 2013. Todos os critérios de desempenho em relação à conforto ambiental foram baseados em condições naturais de insolação e ventilação e em relação à reutilização de água. A norma de desempenho visa reduzir a demanda da água da rede pública de abastecimento e o volume de esgoto conduzido para tratamento sem aumento da probabilidade de ocorrência de doenças ou da redução da satisfação do usuário.

Outros aspectos ainda podem ser analisados como conforto tátil e antropodinâmico, que também são abordados pela ABNT NBR 15575/2013, bem como, aspectos de segurança, como segurança estrutural, prevenção contra incêndio etc.

Como exemplo de edificação que empregou aspectos relacionados à alguns itens aqui especificados cita-se o London City Hall em Londres do arquiteto Norman Foster, que contêm alguns aspectos interessantes:

- A forma do edifício foi concebida para ser um paradigma de redução no consumo de energia;

- O seu formato corresponde a uma esfera modificada para minimizar a área da superfície exposta diretamente ao sol;

- A fachada norte, que recebe a menor insolação direta, é revestida em vidro transparente;

- A fachada sul é inclinada de modo a que um pavimento projete sombra sobre o outro;

- A expectativa é de que o edifício consuma $75 \%$ menos energia do que os sistemas tradicionais de ar-condicionado;

- A maioria dos componentes do edifício, inclusive o revestimento dos pisos e carpetes foram produzidos a partir de material reciclado.

\section{4- Etapa: Pós-uso e destinação final}

No check List de Ottman, deve-se se tomar as devidas interrogações para esta etapa: 
- Pode-se projetar produtos para serem duráveis? Permitir um novo preenchimento (usar refil)? Serem reutilizáveis? Fáceis de reparar? Remanufaturados? Recarregados?

- Pode-se recolher produtos ou embalagens de forma a recicla-los ou reutilizá-los?

- Pode-se fazer produtos e embalagens mais seguros para serem dispostos em aterros ou incinerados?

- Pode-se utilizar materiais e ingrediente biodegradáveis ou passíveis de compostagem?

Frente à estes questionamentos, ganha importância relevante o ciclo de vida dos produtos. Quanto maior a sua durabilidade, menor a exploração de recursos naturais, renováveis ou não, menor o consumo de agua e de energia, menor o teor de poluentes gerados nas fábricas e no transporte das matérias-primas e dos produtos.

Neste aspecto, na construção civil, insere-se o conceito de vida útil. Vida útil é o período de tempo em que um edifício e/ou seus sistemas se presta as atividades para as quais foram projetados e construídos, com atendimento dos níveis de desempenho previstos pela ABNT NBR 15575/2013, considerando a periodicidade e a correta execução dos processos de manutenção especificados no respectivo Manual de Uso, Operação e Manutenção.

Assim a Norma introduz o conceito de vida útil de projeto - VUP, que é uma estimativa teórica de tempo que compõe a vida útil. Poderá ou não ser atingida em função da eficiência e constância dos processos de manutenção, cuidados na utilização do imóvel, alterações do clima ou no entorno da obra etc. O projeto deve especificar o valor teórico da Vida Útil de Projeto (VUP) previsto para cada um dos sistemas que o compõem, não inferior ao limite mínimo correspondente estabelecido na Tabela 1 da norma ABNT NBR 15575/2013.

Tabela 1: Prazo de vida útil de projeto

\begin{tabular}{c|c|c|c}
\hline \multirow{2}{*}{ Sistema } & \multicolumn{3}{|c}{ VUP anos } \\
\cline { 2 - 4 } & Nível Mínimo & Nível Intermediário & Nível Superior \\
\hline Estrutura & $\geq 50$ & $\geq 63$ & $\geq 75$ \\
\hline Pisos internos & $\geq 13$ & $\geq 17$ & $\geq 20$ \\
\hline Vedação vertical externa & $\geq 40$ & $\geq 50$ & $\geq 60$ \\
\hline Vedação vertical interna & $\geq 20$ & $\geq 25$ & $\geq 30$ \\
\hline Cobertura & $\geq 20$ & $\geq 25$ & $\geq 30$ \\
\hline Hidrossanitário & $\geq 20$ & $\geq 25$ & $\geq 30$
\end{tabular}

Fonte: adaptado da NBR 15575/2013.

Portanto, foram analisados os quatro aspectos do check list de Ottman de forma detalhada, com enfoque na construção civil. Com base nas considerações analisadas, apresentase abaixo um check list com questões a serem respondidas para cada fase da edificação, desde sua construção, até sua devida utilização. 
Tabela 2: Check List para construção civil

Questões para cada fase de uma edificação

\begin{tabular}{|c|c|}
\hline $\begin{array}{l}\text { Definição da matéria- } \\
\text { prima e técnicas } \\
\text { construtivas a ser } \\
\text { utilizada na construção } \\
\text { de uma edificação }\end{array}$ & $\begin{array}{l}\text { É possível empregar materiais não-convencionais que geram menos impactos } \\
\text { ambientais? } \\
\text { É possível empregar técnicas construtivas menos agressivas ao meio ambiente? }\end{array}$ \\
\hline Construção da Edificação & $\begin{array}{l}\text { É possível implantar um planejamento eficiente das etapas da obra para evitar } \\
\text { retrabalhos e desperdícios? } \\
\text { É possível empregar um sistema de gerenciamento de resíduos sólidos eficaz? } \\
\text { É possível verificar a destinação final dos resíduos sólidos gerados pela } \\
\text { construção? } \\
\text { Como reduzir o consumo de água e energia? } \\
\text { Como reduzir as emissões e os efluentes? }\end{array}$ \\
\hline Uso & $\begin{array}{l}\text { É possível trabalhar a reutilização de água pluviais ou águas servidas? } \\
\text { É possível trabalhar com energia solar ou fontes alternativas de energia? } \\
\text { Como melhorar o desempenho térmico e lumínico da edificação? }\end{array}$ \\
\hline Pós-Uso & $\begin{array}{l}\text { Como aprimorar a vida útil da edificação? } \\
\text { Como implantar um eficiente sistema de manutenção, uso e operação da } \\
\text { edificação? }\end{array}$ \\
\hline
\end{tabular}

Fonte: elaborado pelos autores

Após todas as considerações apresentadas, é imperioso ressaltar que é possível otimizar o desempenho ambiental do produto, respeitando a legislação ambiental brasileira, e é nesse ponto que é interessante analisar a interface entre o Ecodesign e o Direito.

\section{INTERFACE ENTRE ECODESIGN E O DIREITO FUNDAMENTAL AO MEIO AMBIENTE ECOLOGICAMENTE EQUILIBRADO}

Em aspectos mais específicos, as resoluções CONAMA e as normas da ABNT trazem regulamentações em diversas áreas. Como citado, a norma ABNT NBR 15575/2013 inova trazendo parâmetros para o desempenho de edifícios habitacionais, trazendo vários aspectos visando a sustentabilidade. A Resolução CONAMA 307/2002 denota aspectos relacionados à destinação de resíduos da construção civil. Além destas, várias outras resoluções e normas trazem aspectos ambientais a serem obedecidos.

A Figura 5 mostra a interface dos aspectos observados pelo Ecodesign e pelo Direito. 


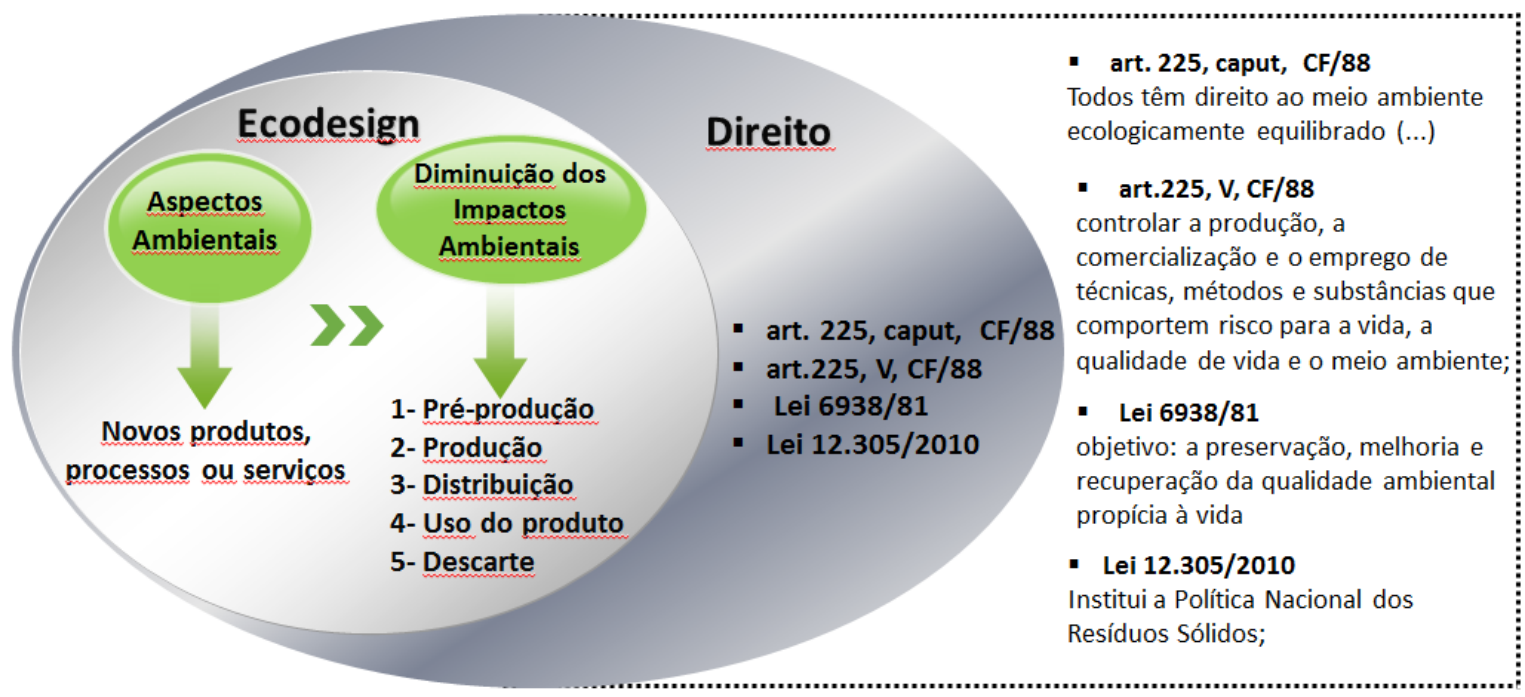

Figura 5: Interface do Ecodesign e do Direito em relação aos aspectos ambientais. Fonte: elaborado pelos autores

Conforme já mencionado anteriormente, é possível identificar que o Ecodesign é uma ferramenta que visa atender os anseios do texto constitucional (art. 225, caput, CF/88, art.225, V, CF/88), legislações infraconstitucionais (Lei 6938/81, Resolução 237 e 307 Conama e Lei 12.305/2010) e normas regulamentadoras (ABNT NBR 15575/2013).

É possível estabelecer uma íntima relação entre os comandos constitucionais e o Ecodesign a partir de aspectos relacionados ao Princípio da Precaução. Esse princípio indica uma ideia de antecipação demonstrando a necessidade de medidas ambientais eficazes para que o dano ambiental não ocorra. Segundo Sands (1995), o princípio da precaução requer que atividades e substâncias nocivas ao meio ambiente sejam controladas e possivelmente proibidas, mesmo sem uma evidência conclusiva ou predominantemente sobre o que o dano ou provável dano causa ao meio ambiente.

Dessa forma, o recurso ao princípio da precaução, como forma de compreender a íntima relação entre o Ecodesign e o Direito Fundamental ao Meio Ambiente Ecologicamente Equilibrado insculpido na Carta Magna pressupõe, como diz Carvalho (2008), a identificação dos efeitos potencialmente perigosos decorrentes de um fenômeno, de um produto ou processo que para o estudo em tela está consubstanciado nos efeitos da utilização desmedida dos recursos naturais (matéria-prima) na construção civil.

A Lei que institui a Política Nacional do Meio Ambiente (Lei n. 6938/81) também possui diretrizes perfeitamente interligadas com a gestão do meio ambiente, propriamente por meio da utilização do Ecodesign. Nos termos dessa lei, a compatibilização do desenvolvimento econômico-social, com a preservação da qualidade do meio ambiente e equilíbrio ecológico devem estar incorporadas nas atividades que direta ou indiretamente afetem as condições estéticas ou sanitárias do meio ambiente (art. 2으, art. 3으 e art. 4으 da Lei n. 6938/81).

Nas fases da construção da edificação, uso e pós-uso, é possível também associar alguns dispositivos jurídicos que podem reforçar o ideal de garantia da sustentabilidade na construção civil. 
Gunther (2011) aponta que o desenvolvimento socioeconômico e o vigente modelo capitalista de produção e consumo têm derivado em grande geração de resíduos de todo o tipo, de um modo difuso. Para a mesma autora, o fluxo dos diferentes tipos de resíduos gerados na sociedade pode gerar graves impactos ambientais, e as consequências sobre a saúde humana poderão ter lugar durante todo o ciclo de vida de um produto.

Nesse sentido, a constatação de que os resíduos gerados por determinadas atividades (inclusive a construção civil) é capaz de trazer prejuízos ambientais incontornáveis, é que se legitima a criação de uma cadeia de procedimentos de gerenciamento desses resíduos, que contemple desde o seu fluxo até a disposição final. Neste contexto, a exata compreensão dos preceitos gerais na lei que institui a Política Nacional dos Resíduos Sólidos (Lei n. 12.305/2010) pode ser estratégia eficaz para a manutenção do equilíbrio ecológico das atividades que envolvem a construção civil. Nos termos dessa lei, o que deve prevalecer é a responsabilidade compartilhada pelo ciclo de vida dos produtos, sem prejuízo de estabelecimento de hierarquia para a gestão dos resíduos: não geração, redução, reutilização, reciclagem, tratamento e disposição final dos rejeitos. Registra-se, ainda, que a referida lei obriga a estruturação e implantação de sistemas de logística reversa, por meio do retorno dos resíduos pós-consumo (Gunther, 2011).

Portanto, entende-se que é de fundamental importância a observância da legislação vigente, e dos preceitos do Ecodesign para que se atinja o direito fundamental ao meio ambiente ecologicamente equilibrado.

\section{CONSIDERAÇÕES FINAIS}

Apesar de ser um setor reconhecido por se importante para o desenvolvimento econômico e social das cidades, a construção civil é uma atividade que causa muitos impactos ambientais. O grande consumo de matéria-prima e energia, e a intensa produção de resíduos, entre outros impactos, contribuem muito para a degradação ambiental. É dentro deste contexto, que se considera relevante a implementação de conceitos de gestão ambiental como objetivos primordiais a serem atingidos por empresas deste setor produtivo. O resultado são obras menos impactantes aos recursos naturais e edificações mais sustentáveis.

Seguindo esse posicionamento, o setor da construção civil deve elaborar alternativas ambientais importantes para viabilizar a utilização eficiente em todas as etapas do ciclo de vida dos produtos gerados, o que denota a imprescindibilidade de apontar os vários tipos de impactos no processo produtivo para, dessa forma, ajustar as medidas práticas para as atividades de construção, atendendo sempre ao arcabouço legal da temática ambiental.

É neste ponto que se verificam os ganhos entre a interface dos conceitos do Ecodesign e do Direito. Pois, ao observar a legislação, inserindo os aspectos ambientais na concepção de produtos, a utilização do Ecodesign torna-se um instrumento para a implementação da qualidade ambiental, e assim contribui para o direito de todo cidadão ao meio ambiente ecologicamente equilibrado.

Nessa perspectiva, ressalta-se que só com o esforço duradouro na gestão ambiental, será possível a criação de condições favoráveis ao equilíbrio entre os processos produtivos, os produtos e a sustentabilidade. 
Portanto, a contribuição desse trabalho é demonstrar a relevância do Ecodesign como uma ferramenta de gestão ambiental no setor da construção civil, de forma que os resultados obtidos garantirão construções com baixo impacto ambiental em todas as suas fases, e consequentemente oferecendo uma contribuição direta para melhoria da sustentabilidade.

\section{REFERÊNCIAS}

Annes, J. (2003). Desenvolvimento de uma metodologia de manufatura consciente para micro, pequenas e médias empresas industriais (Dissertação de Mestrado). Universidade Federal do Rio Grande do Sul, Porto Alegre, RS, Brasil.

Associação brasileira de normas técnicas (2013). NBR 15575: Desempenho de Edificações Habitacionais. Rio de Janeiro, RJ: ABNT.

Beck, U., Giddens, A., \& Lash, S. (1997). Modernização reflexiva: política, tradição e estética na ordem social moderna. São Paulo: UNESP.

Carvalho, D. W. (2008). Dano ambiental futuro. A responsabilização civil pelo risco ambiental. Rio de Janeiro: Forense Universitária.

Ghavami, K. (1993). Bambu como um material para construção. Revista OMRAN, 10(1), 45-48.

Gunther, W. (2011). Gestão de Resíduos Sólidos: uma questão de saúde nas cidades. In C. T. Irigaray. (coord.). PNMA: 30 anos da Política Nacional de Meio Ambiente. São Paulo: Imprensa Oficial.

Lamberts, R., Dutra, L., \& Pereira, F. O. R. (2014). Eficiência Energética na Arquitetura (3a ed). São Paulo: PW.

Leite, J. R. M (Org.). (2010). Direito Constitucional Ambiental Brasileiro (2a ed. ver.). São Paulo: Saraiva.

Leite, J. R. M., \& Ayala, P. A (2011). Dano Ambiental. Do Individual ao coletivo extrapatrimonial. Teoria e Prática. São Paulo: Editora Revista dos Tribunais.

Leff, E. (2000). Ecologia, Capital e Cultura. Racionalidade ambiental, democracia participativa e desenvolvimento sustentável. (J. E. da Silva, Trad.). (Coleção Sociedade e Ambiente). Blumenau: FURB.

Ministério do Meio Ambiente - MMA (2011). Ecodesign. Recuperado de: http://www.mma.gov.br/br

Nascimento, L. F., \& Venzke, C. S. (2006). Ecodesign. In A. Vilela Júnior, \& J. Demajorovic (Orgs.). Modelos e ferramentas de gestão ambiental. Desafios e perspectivas para as organizações (pp. 285-312). São Paulo: Editora Senac.

Ottman, J. A. (2007). Green Marketing: Opportunity for innovation (2a ed). Chicago: NTC.

Pereira, V. C. S (2009). A escassez da Água. (Monografia de Pós graduação Lato Sensu). Universidade Candido Mendes, Rio de Janeiro, RJ, Brasil.

Queiroz, R., Capello, G., \& Wenzel, M. (2007). Bambu, madeira do futuro. Revista Arquitetura \& Construção.

Recuperado

de http://planetasustentavel.abril.com.br/noticia/casa/conteudo_234776.shtml

Resolução CONAMA n 237 (1997). MMA. Legislação Ambiental. Conselho Nacional do Meio 
Ambiente. Recuperado de http://www.mma.gov.br/conama/

Resolução CONAMA n 307 (2002). MMA. Legislação Ambiental. Conselho Nacional do Meio Ambiente. Recuperado de http://www.mma.gov.br/conama/

Sands, P. (2005). Principles of Internacional Environmental Law. Manchester: Manchester University Press.

Vichi, F. M., \& Mansor, M. T. C. (2009). Energia, Meio Ambiente e Economia: o Brasil no contexto mundial. Revista Quim. Nova, 32(3), 757-767. 